\title{
Epidemiology of chronic airway disease: results from a cross-sectional survey in Beijing, China
}

\author{
Hong Zhang ${ }^{1,2 \#}$, Li Dong ${ }^{3 \#}$, Yi-Kun Kang ${ }^{1,2 \#}$, Yong Lu ${ }^{1,2}$, Hui-Hong Wei ${ }^{1,2}$, Jie Huang ${ }^{1,2}$, Xue Wang ${ }^{1,2}$, \\ Kewu Huang ${ }^{1,2}$
}

${ }^{1}$ Beijing Key Laboratory of Respiratory and Pulmonary Circulation Disorders, Department of Pulmonary and Critical Care Medicine, Beijing Chaoyang Hospital, Capital Medical University, Beijing 100020, China; ${ }^{2}$ Beijing Institute of Respiratory Medicine, Beijing 100020, China; ${ }^{3}$ Beijing Tongren Eye Center, Beijing Key Laboratory of Intraocular Tumor Diagnosis and Treatment, Beijing Ophthalmology \& Visual Sciences Key Lab, Beijing Tongren Hospital, Capital Medical University, Beijing 100730, China

Contributions: (I) Conception and design: H Zhang, K Huang; (II) Administrative support: H Zhang, Y Lu, K Huang; (III) Provision of study materials or patients: H Zhang, Y Lu, K Huang; (IV) Collection and assembly of data: L Dong, YK Kang; (V) Data analysis and interpretation: L Dong, YK Kang, HH Wei, J Huang, X Wang; (VI) Manuscript writing: All authors; (VII) Final approval of manuscript: All authors.

\#These authors contributed equally to this work.

Correspondence to: Kewu Huang, MD. Department of Pulmonary and Critical Care Medicine, Beijing Chaoyang Hospital, Capital Medical University, No. 8, Gongti South Road, Chaoyang District, Beijing 100020, China. Email: kewuhuang@126.com.

Background: Although the epidemiology of chronic airway disease (CAD) has been investigated in several population-based studies, the findings of these studies are diverse. We aimed to investigate the prevalence of CAD and its associated factors in urban northern China.

Methods: A cross-sectional study was conducted among 29,359 Chinese adults aged $\geq 20$ years. All participants were randomly recruited from two urban communities in Beijing and asked to complete a selfadministered questionnaire that enquired about the demographic characteristics as well as the diagnosis of CAD and CAD-related symptoms.

Results: In all, 26,166 participants completed the questionnaire, with the response rate being $89.1 \%$. The prevalence of diagnosed CAD was $9.0 \%$ among men and $7.2 \%$ among women, with a total prevalence of $8.1 \%$. Furthermore, $11.5 \%$ of the investigated subjects had CAD-related symptoms. Women had a lower risk of developing wheezing, cough, dyspnea, and diagnosed $\mathrm{CAD}$ than men $(\mathrm{P}<0.05)$. The frequency of CAD-related symptoms and diagnosed CAD was greater among elderly persons than among those who were younger $(\mathrm{P}<0.01)$. Subjects with a smoking habit were more susceptible to CAD-related symptoms and diagnosed $\mathrm{CAD}(\mathrm{P}<0.01)$. Additionally, individuals with $\mathrm{CAD}$-related symptoms were more likely to be diagnosed with $\mathrm{CAD}$, compared to those without these symptoms $(\mathrm{P}<0.01)$.

Conclusions: CAD is a common respiratory disease in urban northern China. Female gender might be a protective factor against $\mathrm{CAD}$, while age and smoking are risk factors for the disease.

Keywords: Epidemiology; chronic airway disease (CAD); chronic bronchitis (CB); emphysema; asthma

Submitted Jul 05, 2018. Accepted for publication Sep 30, 2018.

doi: $10.21037 /$ jtd.2018.10.44

View this article at: http://dx.doi.org/10.21037/jtd.2018.10.44

\section{Introduction}

With the growth of the aging and smoking populations, there has been a considerable increase in the occurrence of chronic airway disease (CAD), which is associated with a high morbidity and significant burden of disability, resulting in substantial strain on the national health care budget. With the high prevalence of chronic obstructive pulmonary disease (COPD) and asthma, CAD is becoming one of the most important public health concerns $(1,2)$.

Chronic bronchitis (CB) is a common but variable 
manifestation of COPD that is defined by the presence of chronic productive cough for at least 3 months per year for two consecutive years. It is associated with several clinical sequelae, including an accelerated decline in lung function and a high risk of airflow obstruction $(3,4)$. Emphysema is another form of COPD, which mainly presents with dyspnea (5). Asthma is yet another kind of CAD, which is often regarded as a heterogeneous disease. It affects more than 300 million people worldwide and is predicted to affect an additional 100 million people by the year 2025 (6).

Research has shown that the primary risk factor for $\mathrm{CB}$ is smoking, which is evident from the cumulative 30-year incidence of $\mathrm{CB}$, which is $42 \%$ in current smokers (7). However, it should be noted that $\mathrm{CB}$ also has been described in $22 \%$ of those who have never smoked (8), suggesting the existence of other risk factors besides smoking. Many studies have shown that CB affects men more than women. However, according to the 2009 National Center for Health Statistics report, $67.8 \%$ of patients with CB were women and women had more frequent episodes of exacerbation as compared to men (9). The factors contributing to the development of emphysema and asthma also remain debatable (10).

To the best of our knowledge, studies on the epidemiology of CAD (including $\mathrm{CB}$, emphysema, and asthma) in the Chinese population are limited. Therefore, we conducted a cross-sectional investigation in northern Chinese urban communities. This study aimed to assess the epidemiological characteristics of $\mathrm{CAD}$, including its prevalence and associations with demographic characteristics and smoking habit. We believe that these data will provide insights into the scientific and theoretical basis of screening strategies for CAD in China.

\section{Methods}

\section{Participants}

This study was conducted in the administrative area of Beijing, which is the most populous area in the Chaoyang District. Two urban subdistricts, namely Liulitun and Hujialou, were randomly selected from the medical conjoined network system of the Chaoyang Hospital Medical Association. Each of the subdistricts had 10 communities, of which two were randomly selected. Between March 1, 2015, and November 30, 2015, a total of 32,125 questionnaires were distributed among all residents of the selected communities who were above 20 years of age. Responses were collected for 29,359 questionnaires (response rate, 91.4\%), with 26,166 (89.1\%) being valid. Thus, a total of 26,166 participants were included in this survey.

Based on previous reports, the prevalence rate of asthma in the national community was reported to be about $\mathrm{P}=2 \%$ (with the lowest calculated basis) (11); the allowable error of the survey was set to $0.2 \%$, alpha $=0.05$, with the formula based on the cross-sectional study being $\mathrm{n}=(\mathrm{Z} 1-\mathrm{alpha} / 2 /$ delta) 2 P (1-p). Thus, the calculated sample volume was 18,824 cases, considering the sampling error of cluster sampling. Furthermore, to expand the sample size by $20 \%$, the total number of samples needed was $18,824 \times 1.2=22,588$. The number of samples included in this study was 26,166 , indicating that the sample size requirement was successfully met.

The study protocol was approved by the Human Ethics Committee of Beijing Chaoyang Hospital (2013-ke-163), and informed consent was obtained from all participants.

\section{Data collection}

All participants were personally interviewed by medical doctors and trained nurses at the Health Service Center and asked to complete a standardized screening questionnaire. The questionnaire covered details regarding the demographic characteristics, diagnosis of $\mathrm{CAD}$, and CADrelated symptoms. In the questionnaire, the CAD-related symptoms were described in a manner similar to that described in the European Community Respiratory Health Survey (ECRHS) (12): (I) wheezing: "Have you had wheezing or whistling in your chest at any time in the last 12 months?" and "Have you been at all breathless when the wheezing noise was present?"; (II) chronic cough: "Do you usually have a cough without a cold?" and "Do you cough like this for as much as 3 months each year?"; (III) chronic phlegm: "Do you usually have phlegm first thing in the morning?" and "Do you usually have phlegm like this for as much as 3 months each year?"; (IV) dyspnea: "Have you been woken by an attack of shortness of breath at any time in the last 12 months?"

The questions pertaining to doctor-diagnosed $\mathrm{CAD}$ were as follows: (I) CB: "Have you ever been diagnosed with CB by a doctor?"; (II) emphysema: "Have you ever been diagnosed with emphysema by a doctor?"; (III) asthma: "Have you ever been diagnosed with asthma by a doctor?"

In addition, details regarding gender, age, and smoking habit were also collected in the questionnaire. Current smokers were defined as those who had smoked within the 
Table 1 Characteristics of the participants by age group

\begin{tabular}{|c|c|c|c|c|c|c|}
\hline Characteristics & \multicolumn{5}{|c|}{ Age (years) } & Total \\
\hline Subjects (n) & 2,920 & 4,347 & 4,413 & 6,903 & 7,583 & 26,166 \\
\hline Men (\%) & 48.9 & 47.3 & 50.1 & 49.5 & 47.4 & 48.6 \\
\hline \multicolumn{7}{|l|}{ Smoking habits, n (\%) } \\
\hline Ex-smoker & $50(1.7)$ & $70(1.6)$ & $99(2.2)$ & $215(3.1)$ & $374(4.9)$ & $808(3.1)$ \\
\hline Current smoker & 301 (10.3) & $552(12.7)$ & $773(17.5)$ & $1,284(18.6)$ & $1,274(16.8)$ & $4,184(16.0)$ \\
\hline CAD-related symptoms, n (\%) & & & & & & $3,011(11.5)$ \\
\hline Wheezing & $40(1.4)$ & $60(1.4)$ & $134(3.0)$ & $394(5.7)$ & $712(9.4)$ & $1,340(5.1)$ \\
\hline Dyspnea & $49(1.7)$ & $56(1.3)$ & $95(2.2)$ & $227(3.3)$ & $489(6.4)$ & $916(3.5)$ \\
\hline Doctor-diagnosed CAD, n (\%) & & & & & & $2,122(8.1)$ \\
\hline CB & $51(1.7)$ & $96(2.2)$ & $203(4.6)$ & $524(7.6)$ & $922(12.2)$ & $1,796(6.9)$ \\
\hline Emphysema & $8(0.3)$ & $26(0.6)$ & $44(1.0)$ & $87(1.3)$ & $183(2.4)$ & 348 (1.3) \\
\hline Asthma & $21(0.7)$ & $33(0.8)$ & $70(1.6)$ & $150(2.2)$ & 369 (4.9) & $643(2.5)$ \\
\hline
\end{tabular}

$\mathrm{CAD}$, chronic airway disease; $\mathrm{CB}$, chronic bronchitis.

last one month, whereas nonsmokers were those who had never smoked; the remaining persons were classified as ex-smokers.

\section{Statistical analysis}

Double data entry and consistency checking were processed using EpiData 3.1. All statistical analyses of data were performed using SPSS 22.0 (IBM Corp., Armonk, NY, USA). Continuous variables such as age were represented as the median $\left(25^{\text {th }}\right.$ percentile value and $75^{\text {th }}$ percentile value $)$. Data regarding gender, smoking habit, CB, emphysema, asthma, wheezing, cough, phlegm, and dyspnea were presented as categorical variables. Significance tests were analyzed by using the chi-squared test and the Wilcoxon rank sum test for binary categorical variables and other continuous variables, respectively. The prevalence of $\mathrm{CAD}$ and CAD-related symptoms was calculated with 95\% confidence intervals (CIs). Additionally, genderspecific prevalence rates were estimated for all participants and for each 10-year age group. The logistic regression model was employed to assess the effects of age, gender, and smoking habit on CAD-related symptoms. The same regression model was also applied to determine the effects of demographic characteristics and CAD-related symptoms on CAD. Adjusted odds ratios (ORs) for all factors were estimated by the logistic regression model. $\mathrm{P}<0.05$ was considered to be statistically significant.

\section{Results}

\section{Demographic characteristics of the participants}

The characteristics of the participants classified by age group are shown in Table 1. The numbers of participants in the older age groups were greater than those in the younger age groups. Moreover, 12,711 (48.6\%) subjects were men, and $21,174(80.9 \%)$ subjects were nonsmokers. Additionally, $3,011(11.5 \%)$ subjects responded positively to the presence of CAD-related symptoms, and the numbers (prevalence) of participants with the symptoms of wheezing, cough, phlegm, and dyspnea were 1,340 (5.1\%), 1,894 (7.2\%), $1,570(6.0 \%)$, and 916 (3.5\%), respectively. Furthermore, $2,122(8.1 \%)$ subjects had been diagnosed with CAD at some point in their lives, and the numbers of patients with 
Table 2 Prevalence of CAD-related symptoms and CAD in males by age group $(n=12,711)$

\begin{tabular}{|c|c|c|c|c|c|c|}
\hline Symptoms or CAD & \multicolumn{5}{|c|}{ Age (years) } & Total \\
\hline Symptoms & & & & & & $13.4(12.8-14.0)$ \\
\hline Wheezing & $1.7(1.1-2.4)$ & $1.7(1.1-2.2)$ & $3.5(2.8-4.3)$ & $6.7(5.8-7.5)$ & $11.0(10.0-12.1)$ & $5.9(5.5-6.3)$ \\
\hline Chronic cough & $3.2(2.3-4.1)$ & $3.9(3.1-4.7)$ & $5.4(4.5-6.4)$ & $10.0(9.0-11.0)$ & $13.5(12.4-14.6)$ & $8.4(8.0-8.9)$ \\
\hline Dyspnea & $2.2(1.4-2.9)$ & $1.5(0.9-2.0)$ & $2.4(1.8-3.1)$ & $3.3(2.7-3.9)$ & $6.7(5.9-7.6)$ & $3.7(3.4-4.0)$ \\
\hline Doctor-diagnosed CAD & & & & & & $9.0(8.5-9.5)$ \\
\hline $\mathrm{CB}$ & $2.5(1.7-3.3)$ & $2.8(2.1-3.5)$ & $5.3(4.4-6.3)$ & $8.0(7.1-8.9)$ & $12.9(11.8-14.0)$ & $7.5(7.0-7.9)$ \\
\hline Emphysema & $0.2(0.0-0.4)$ & $0.5(0.2-0.8)$ & $1.3(0.8-1.7)$ & $1.5(1.1-1.9)$ & $3.1(2.5-3.6)$ & $1.6(1.4-1.8)$ \\
\hline
\end{tabular}

All data are presented as percentages (95\% Cls). $\mathrm{P}<0.001$ between age groups for all CAD-related symptoms and CAD (chi-squared test). $\mathrm{CAD}$, chronic airway disease; $\mathrm{CB}$, chronic bronchitis.

Table 3 Prevalence of CAD-related symptoms and CAD in females by age group $(n=13,455)$

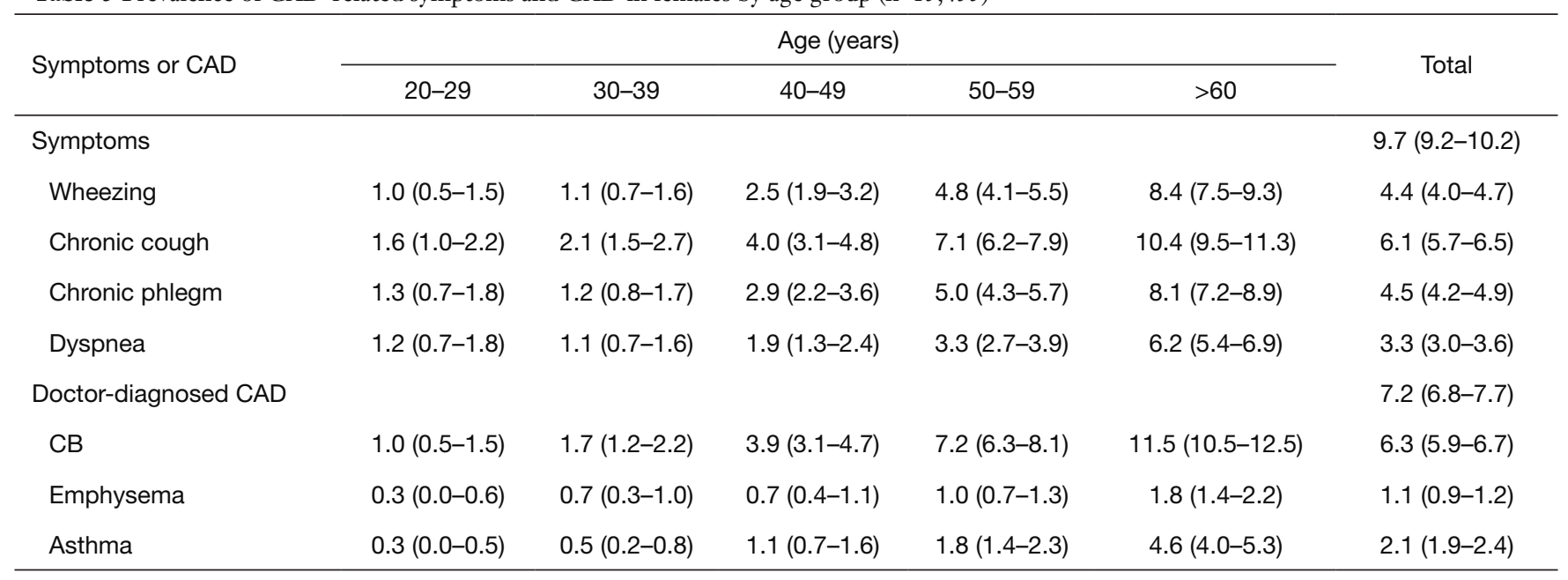

All data are presented as percentages (95\% Cls). $\mathrm{P}<0.001$ between age groups for all CAD-related symptoms and CAD (chi-squared test). $\mathrm{CAD}$, chronic airway disease; $\mathrm{CB}$, chronic bronchitis.

CB, emphysema, and asthma were $1,796(6.9 \%), 348(1.3 \%)$, and $643(2.5 \%)$, respectively; $203(0.8 \%)$ subjects were diagnosed with both CB and emphysema, and 423 (1.6\%) subjects were diagnosed with both $\mathrm{CB}$ and asthma.

\section{Gender-specific prevalence of CAD and CAD-related symptoms}

The prevalence rates of CAD and CAD-related symptoms are shown separately for males and females in Tables 2,3.
Approximately $9.0 \%$ subjects in men and $7.2 \%$ in women had been diagnosed with CAD at some point in their lives. In addition, $13.4 \%$ of the men and $9.7 \%$ of the women had CAD-related symptoms. The prevalence of wheezing was $1.7 \%$ in participants aged $20-29$ years and $11.0 \%$ among those aged $>60$ years among men, with the rates increasing from $1.0 \%$ to $8.4 \%$ among women. The prevalence rates of most symptoms and CAD also increased markedly with age, in both men and women. The prevalence rates of most $\mathrm{CAD}$ and CAD-related symptoms were higher among men 
Table 4 The effects of age, gender, and smoking on the CAD-related symptoms and CAD

\begin{tabular}{lccccc}
\hline Symptoms or CAD & Demographic characteristics & B & SE & P & OR (95\% Cl) \\
\hline Wheezing & Female & -0.18 & 0.07 & 0.01 & $0.84(0.73-0.96)$ \\
& Age & 0.04 & $<0.01$ & $<0.01$ & $1.04(1.04-1.05)$ \\
Chronic cough & Smoking & 1.14 & 0.07 & $<0.01$ & $3.12(2.72-3.59)$ \\
& Female & -0.14 & 0.06 & 0.02 & $0.87(0.78-0.98)$ \\
Chronic phlegm & Age & 0.03 & $<0.01$ & $<0.01$ & $1.03(1.03-1.04)$ \\
& Smoking & 0.14 & 0.06 & $<0.01$ & $3.12(2.78-3.52)$ \\
& Female & -0.01 & 0.07 & 0.91 & $0.99(0.87-1.13)$ \\
Dyspnea & Age & 0.04 & $<0.01$ & $<0.01$ & $1.04(1.03-1.04)$ \\
& Smoking & 1.27 & 0.07 & $<0.01$ & $3.57(3.14-4.05)$ \\
CB & Female & -0.67 & 0.09 & $<0.01$ & $0.51(0.43-0.61)$ \\
& Age & 0.04 & $<0.01$ & $<1.01$ & $1.04(1.04-1.04)$ \\
& Smoking & 1.60 & 0.09 & $<0.01$ & $4.98(4.19-5.91)$ \\
Esthma & Female & -0.47 & 0.06 & $<0.01$ & $0.63(0.55-0.71)$ \\
& Age & 0.04 & $<0.01$ & $<0.01$ & $1.04(1.04-1.05)$ \\
& Smoking & 1.42 & 0.06 & $<0.01$ & $4.12(3.63-4.67)$ \\
& Female & -0.71 & 0.14 & $<0.01$ & $0.49(0.37-0.65)$ \\
\hline Age & 0.04 & $<0.01$ & $<0.01$ & $1.04(1.03-1.04)$ \\
& Agmeking & 2.16 & 0.14 & $<0.01$ & $8.66(6.56-11.43)$ \\
& Female & -0.72 & 0.11 & $<0.01$ & $0.49(0.40-0.60)$ \\
& Age & 0.05 & $<0.01$ & $<0.01$ & $1.05(1.04-1.05)$ \\
& 1.94 & 0.18 & $<0.01$ & $6.98(5.68-8.57)$ \\
\hline
\end{tabular}

$\mathrm{CB}$, chronic bronchitis; CAD, chronic airway disease; SE, standard error; OR, odds ratio; CI, confidence interval.

than among women.

\section{Effects of age, gender, and smoking on the CAD and CAD- related symptoms}

The effects of age, gender, and smoking on the prevalence of CAD and CAD-related symptoms are elucidated in Table 4. Older people appeared to have a higher prevalence of $\mathrm{CAD}$ related symptoms and $\mathrm{CAD}(\mathrm{P}<0.05, \mathrm{OR}>1.00)$ as compared to those younger. Moreover, participants who were smokers were more likely to develop CAD and CAD-related symptoms, particularly dyspnea $(\mathrm{P}<0.05, \mathrm{OR}>1.00)$. Gender was yet another significant factor influencing the prevalence of CAD and CAD-related symptoms, with women having a lower possibility of developing wheezing, cough, and dyspnea $(\mathrm{P}<0.05, \mathrm{OR}<1.00)$. However, no significant differences were noted between the two genders in terms of the prevalence of phlegm $(\mathrm{P}>0.05)$. In addition, women had a lower risk of $\mathrm{CAD}$ and $\mathrm{CAD}$-related symptoms $(\mathrm{P}<0.05$, $\mathrm{OR}<1.00)$.

\section{Discussion}

To date, only a few studies have used a standardized questionnaire to determine the prevalence of doctordiagnosed CAD and CAD-related symptoms in Chinese adults. The use of a standardized questionnaire allowed for the comparison between the results obtained using the same questionnaire in other countries. The current study is the first large-scale investigation on CAD and related respiratory symptoms performed in Beijing, China. The present study estimated an $8.1 \%$ pooled prevalence of 
CAD among adults aged 20 years and above in Beijing, China. Our study also revealed that more than $11.5 \%$ of the population had CAD-related symptoms, with cough being the most common one. The prevalence of CAD and CAD-related symptoms increased with age, which is consistent with the findings of a similar previous study (13). The prevalence of doctor-diagnosed asthma was $2.5 \%$, which is higher than $1.19 \%$ reported from Beijing 5 years ago (13). In the present study, a standard questionnaire was used to determine the prevalence of wheezing - the typical symptom of asthma; our results indicated a prevalence of $5.1 \%$, which is more than two times that of doctordiagnosed asthma. Therefore, it would be reasonable to infer that the actual prevalence of asthma in Beijing may be underestimated. In addition, the prevalence of asthma and asthma-like symptoms in urban communities of Beijing has been reported to be higher than that in rural Beijing (14).

The prevalence of $\mathrm{CB}$ in our study was $6.9 \%$, which is higher than that in Canada (2.5\%), India (3.5\%), Iran (5.6\%), Vietnam (5.6\%), and Australia (6.1\%) (15-19), but lower than that in European countries such as Sweden (7.2\%) and Turkey (14.1\%) (20,21). Chronic cough and chronic phlegm are symptoms associated with $\mathrm{CB}$. The prevalence of bronchitis-related symptoms in China has been reported to be lower than that in Serbia (22). Furthermore, it increased with age, as was the case with bronchitis, which is consistent with previous reports $(13,14)$. In addition, the prevalence of bronchitis-related symptoms observed in our study was higher than that reported in rural Beijing (14). The reasons for the variability in the prevalence reported in different areas are not entirely clear. Considerable regional differences are noted in the prevalence of some risk factors known to be associated with CAD, such as environmental exposure to pollutants, smoking rate, lag effect of smoking, extent of urbanization, air pollution, health surveys, diagnostic facilities, geographical and seasonal variations, as well as genetic and ethnic factors (23). Their actual roles, however, still remain to be determined. CB is often regarded as the early stage of COPD and has attracted considerable research interest. Some epidemiological characteristics of CB have been reported from different regions of the world. Pelkonen et al. (24) have examined the trends in the prevalence of $\mathrm{CB}$ during the last three decades and have reported a decrease in the prevalence from $19 \%$ and $13 \%$ to $13 \%$ and $11 \%$ in men and women, respectively, between the ages of 25 and 64 years. This decrease may be attributed to advances in medicine and timely treatment. However, Accordini et al. (25) have found that despite the significant reduction in the percentage of persons currently smoking, the prevalence of $\mathrm{CB}$ did not vary among young Italian adults, indicating the role of other influencing factors. Since the proportion of $\mathrm{CB}$ patients continues to remain high, the condition is still a cause for concern.

Studies investigating the epidemiology of emphysema are limited. The current study showed that the prevalence of emphysema in a Chinese population was $1.3 \%$, which is lower than that reported in the US (3.0\%) (26). In addition, about $3.5 \%$ of subjects in our study population had emphysema-related symptoms. Emphysema is a type of dormant disease that can occur as the consequence of severe $\mathrm{CB}, \mathrm{COPD}$, and pulmonary fibrosis, especially in smokers $(27,28)$. Although some studies have shown a decrease in the prevalence of emphysema among men due to the significant reduction of smoking rates (29), it still remains a topic of concern.

Another interesting finding of our study was that the number of people with a doctor-diagnosis of CAD (including $\mathrm{CB}$, asthma and emphysema) is higher than the total participant number. Further analysis also confirmed there were several overlaps in the patients with different kinds of CAD, which is similar to some former research (30).

In the present study, age, male gender, and smoking were determined to be risk factors of CAD and CAD-related symptoms, which is consistent with the findings of some previous studies (31). Smoking is a widely accepted risk factor of CAD in many other studies (32). For example, research carried out by Forey et al. (33) has demonstrated a clear relationship between smoking and the outcomes of COPD, CB, and emphysema. An important finding in our study is that smoking may also serve as a risk factor for asthma and not only for the exacerbation of asthma as is currently believed. In addition, our results also show the female gender is a protective factor for CAD and CADrelated symptoms, which does not agree with the findings of some previous studies (34). On the contrary, some other studies have reported that women were more susceptible to some chronic respiratory diseases due to physiological structural characteristics, exposure to second-hand smoke, and higher sensitivity to symptoms $(35,36)$. These contradictory opinions might be attributed to differences in the selected population samples. With the increase in efforts to discourage smoking worldwide, air pollution might become the new global challenge and could greatly affect the epidemiological characteristics of CAD $(37,38)$. Therefore, further investigations in this line of research are 
imperative.

This study does have some limitations that need to be acknowledged. First, the possibility of inaccurate answers in self-reported questions must be taken into consideration, particularly in the case of participants with a low education level. Second, no associated factors were included in the questionnaire employed in this study. Third, the proportion of older participants in this study population was high, which could lead to some degree of bias. Moreover, the low prevalence of wheezing and dyspnea could be partly attributed to the improper understanding of the terms by the participants.

\section{Conclusions}

CAD is a common respiratory disease in Beijing, China, with an estimated prevalence of $8.1 \%$. The prevalence rates of $\mathrm{CB}$, emphysema and asthma diagnosed by doctor in the Chinese population were $6.9 \%, 1.3 \%$, and $2.5 \%$, respectively. It appears that the actual prevalence of asthma might be underestimated. The female gender appeared to be a protective factor for CAD and CAD-related symptoms, while old age and smoking habit were found to be risk factors.

\section{Acknowledgements}

Funding: This study was supported by grants from the National Natural Science Foundation of China (81470238, 81670032) and the National Key Research and Development Program of China (2016YFC0901102).

\section{Footnote}

Conflicts of Interest: The authors have no conflicts of interest to declare.

Ethical Statement: The study protocol was approved by the Human Ethics Committee of Beijing Chaoyang Hospital (2013-ke-163), and informed consent was obtained from all participants.

\section{References}

1. GOLD Executive Committee. Global strategy for the diagnosis, management, and prevention of chronic obstructive pulmonary disease (Updated 2017). Available online: http://www.goldcopd.com
2. Global Initiative for Asthma. Global strategy for asthma management and prevention, 2018. Available online: http://www.ginasthma.org

3. Burgel PR, Nesme-Meyer P, Chanez P, et al. Cough and sputum production are associated with frequent exacerbations and hospitalizations in COPD subjects. Chest 2009;135:975-82.

4. Guerra S, Sherrill DL, Venker C, et al. Chronic bronchitis before age 50 years predicts incident airflow limitation and mortality risk. Thorax 2009;64:894-900.

5. Stolk J, Putter H, Bakker EM, et al. Progression parameters for emphysema: a clinical investigation. Respir Med 2007;101:1924-30.

6. Masoli M, Fabian D, Holt S, Beasley R. The global burden of asthma: executive summary of the GINA Dissemination Committee report. Allergy 2004;59:469-78.

7. Pelkonen M, Notkola IL, Nissinen A, et al. Thirty-year cumulative incidence of chronic bronchitis and COPD in relation to 30-year pulmonary function and 40-year mortality: a follow-up in middle-aged rural men. Chest 2006;130:1129-37.

8. Miravitlles M, De La Roza C, Morera J, et al. Chronic respiratory symptoms, spirometry and knowledge of COPD among general population. Respir Med 2006;100:1973-80.

9. Kim V, Criner GJ. Chronic bronchitis and chronic obstructive pulmonary disease. Am J Respir Crit Care Med 2013;187:228-37.

10. Wenzel S. Severe asthma in adults. Am J Respir Crit Care Med 2005;172:149-60.

11. Zhang F, Hang J, Zheng B, et al. The changing epidemiology of asthma in Shanghai, China. J Asthma 2015;52:465-70.

12. European Community Respiratory Health Survey. Variations in the prevalence of respiratory symptoms, selfreported asthma attacks, and use of asthma medication in the European Community Respiratory Health Survey (ECRHS). Eur Respir J 1996;9:687-95.

13. Wang WY, Lin JT, Su N, et al. Survey on the prevalence rate of bronchial asthma in Beijing area among the residents aged over 14 years from 2010 to 2011. Zhonghua Yi Xue Za Zhi 2013;93:1383-7.

14. Chan-Yeung M, Zhan LX, Tu DH, et al. The prevalence of asthma and asthma-like symptoms among adults in rural Beijing, China. Eur Respir J 2002;19:853-8.

15. Karunanayake CP, Hagen B, Dosman JA, et al. Prevalence of and risk factors for chronic bronchitis in a Canadian population: The Canadian Community Health Survey, 
2007 to 2008. Can Respir J 2013;20:231-6.

16. Jindal SK, Aggarwal AN, Gupta D, et al. Indian study on epidemiology of asthma, respiratory symptoms and chronic bronchitis in adults (INSEARCH). Int J Tuberc Lung Dis 2012;16:1270-7.

17. Varmaghani M, Farzadfar F, Sharifi F, et al. Prevalence of asthma, COPD, and chronic bronchitis in Iran: a systematic review and meta-analysis. Iran J Allergy Asthma Immunol 2016;15:93-104.

18. Lâm HT, Rönmark E, Tu'ò'ng NV, et al. Increase in asthma and a high prevalence of bronchitis: results from a population study among adults in urban and rural Vietnam. Respir Med 2011;105:177-85.

19. Dharmage SC, Perret JL, Burgess JA, et al. Current asthma contributes as much as smoking to chronic bronchitis in middle age: a prospective population-based study. Int J Chron Obstruct Pulmon Dis 2016;11:1911-20.

20. Axelsson M, Ekerljung L, Eriksson J, et al. Chronic bronchitis in West Sweden-a matter of smoking and social class. Eur Clin Respir J 2016;3:30319.

21. Tutar N, Yeşilkaya S, Memetoğlu ME, et al. The prevalence of chronic bronchitis in adults living in the center of Gumushane. Tuberk Toraks 2013;61:209-15.

22. Milenković B, Mitić-Milikić M, Rebić P, et al. Asthma and chronic bronchitis symptoms among adult population of Belgrade. Srp Arh Celok Lek 2011;139:149-54.

23. Wang C, Xu J, Yang L, et al. Prevalence and risk factors of chronic obstructive pulmonary disease in China (the China Pulmonary Health $[\mathrm{CPH}]$ study): a national cross-sectional study. Lancet 2018;391:1706-17.

24. Pelkonen MK, Notkola IL, Laatikainen TK, et al. Twenty-five year trends in prevalence of chronic bronchitis and the trends in relation to smoking. Respir Med 2014;108:1633-40.

25. Accordini S, Corsico AG, Cerveri I, et al. Diverging trends of chronic bronchitis and smoking habits between 1998 and 2010. Respir Res 2013;14:16-23.

26. Araki T, Nishino M, Zazueta OE, et al. Paraseptal emphysema: prevalence and distribution on CT and association with interstitial lung abnormalities. Eur J

Cite this article as: Zhang H, Dong L, Kang YK, Lu Y, Wei HH, Huang J, Wang X, Huang K. Epidemiology of chronic airway disease: results from a cross-sectional survey in Beijing, China. J Thorac Dis 2018;10(11):6168-6175. doi: 10.21037/ jtd.2018.10.44
Radiol 2015;84:1413-8.

27. Kim V, Sternberg AL, Washko G, et al. Severe chronic bronchitis in advanced emphysema increases mortality and hospitalizations. COPD 2013;10:667-78.

28. Cottin V. The impact of emphysema in pulmonary fibrosis. Eur Respir Rev 2013;22:153-7.

29. Halldin CN, Doney BC, Hnizdo E. Changes in prevalence of chronic obstructive pulmonary disease and asthma in the US population and associated risk factors. Chron Respir Dis 2015;12:47-60.

30. Bonten TN, Kasteleyn MJ, de Mutsert R, et al. Defining asthma-COPD overlap syndrome: a population-based study. Eur Respir J 2017;49.

31. Rojas M, Mora AL, Kapetanaki M, et al. Aging and lung disease clinical impact and cellular and molecular pathways. Ann Am Thorac Soc 2015;12:S222-7.

32. Koul PA, Hakim NA, Malik SA, et al. Prevalence of chronic airflow limitation in Kashmir, North India: results from the BOLD study. Int J Tuberc Lung Dis 2016;20:1399-404.

33. Forey BA, Thornton AJ, Lee PN. Systematic review with meta-analysis of the epidemiological evidence relating smoking to COPD, chronic bronchitis and emphysema. BMC Pulm Med 2011;11:36-96.

34. Konrad S, Hossain A, Senthilselvan A, et al. Chronic bronchitis in aboriginal people-prevalence and associated factors. Chronic Dis Inj Can 2013;33:218-25.

35. Liptzin DR, Landau LI, Taussig LM. Sex and the lung: observations, hypotheses, and future directions. Pediatr Pulmonol 2015;50:1159-69.

36. Wu CF, Feng NH, Chong IW, et al. Second-hand smoke and chronic bronchitis in Taiwanese women: a health-care based study. BMC Public Health 2010;10:44-53.

37. Salameh P, Salame J, Khayat G, et al. Exposure to outdoor air pollution and chronic bron $\neg$ chitis in adults: a casecontrol study. Int J Occup Environ Med 2012;3:165-77.

38. Cai Y, Schikowski T, Adam M, et al. Cross-sectional associations between air pollution and chronic bronchitis: an ESCAPE meta-analysis across five cohorts. Thorax 2014;69:1005-14. 